International Journal of Electrical and Power Engineering 12 (2): 15-19, 2018

ISSN: 1990-7958

(C) Medwell Journals, 2018

\title{
To Improve Efficiency of Vertical Axis Wind Turbine Components Evaluation
}

\author{
${ }^{1} \mathrm{~K}$. Manikandan and ${ }^{2} \mathrm{~B}$. Justus Rabi \\ ${ }^{1}$ Department of EEE, Jawahar Lal Nehru Technological University Hyderabad (JNTUH), \\ Telegana, India \\ ${ }^{2}$ Department of EEE, Shri Andal Alagar College of Engineering (SAACE), Mamandur, \\ Tamil Nadu, India
}

\begin{abstract}
Wind turbine brake system plays a very critical role in keeping WT operate normally and safely. This study aims to propose a solenoid based electro-hydro-mechanic braking system for WTs by using IoT. This system includes an intelligent control and monitoring system that commits the braking functionality in a more efficient and reliable way in terms of smooth braking performance, value engineering is a proven management technique that can make valuable contributions to value enhancement and cost reduction in wind industry. The overall estimated savings of the project resulting from the full value engineering study ranged between $20-30 \%$ of the element cost; VE is recognized as an effective way to improve the performance of a product with reduction in cost.
\end{abstract}

Key words: Wind brake, solenoid, value engineering, IoT, safely, intelligent

\section{INDRODUCTION}

A wind turbine extracts energy from moving air by slowing the wind down and transferring this energy into a spinning shaft which usually turns a generator to produce electricity. A wind turbine is a rotating machine which converts kinetic energy in wind to electrical energy. The use of wind turbine is important as it is the alternative to other main energy generators. There are two major types of wind turbine determined based on the axis in which the turbine rotates. Horizontal Axis Wind Turbine (HAWT) and Vertical Axis Wind Turbine (VAWT) (Anonymous, 2018). In Wind Energy Conversion Systems (WECSs), the key technologies include wind turbine technology, power electronics technology and system control technology. For the wind turbines, based on the orientation of the rotation axis of the wind turbine there are horizontal-axis wind turbines and vertical-axis wind turbines. The modern engineering design approach can be classified into three subsets, the engineering model, mathematical model and computation model (IEC., 2015).

Efficiency is one of the most important parameters to analyze the performance of a wind turbine design. Efficiency of a wind turbine is expressed usually in terms of flow energy utilization factor and Coefficient of Power (CP) (Froese, 2016). Manual braking is ideal, since, it allows you to stop the machine in all conditions. Drum and disc brakes have been used in a few turbine designs, but most turbines use dynamic or electrical, braking where a big switch opens the connection to the grid or batteries and shorts the three phases of the wind turbine together, a brake controller sends on/off signal to activate/deactivate to DC solenoid (Jee et al., 2012). From the experimental results using test bed in the laboratory it is concluded that when initial rotational speed is $600 \mathrm{rpm}$ the mechanical brake could stop the rotating mass in $1.2 \mathrm{sec}$ under solenoid brake (Meeker and McWilliams, 2003).

\section{MATERIALS AND METHODS}

Electro mechanical brake: A complete wind energy system including rotor, transmission, generator, storage and other devices which all have less than perfect efficiencies will deliver between $10-30 \%$ of the original energy available in the wind. Electromagnetic brakes operate electrically but transmit torque mechanically. This is why they used to be referred to as electro-mechanical brakes. Over the years, EM brakes became known as Electro Magnetic, referring to their actuation method. The variety of applications and brake designs has increased dramatically but the basic operation remains the same. Single face electromagnetic brakes make up approximately $80 \%$ of all of the power applied brake applications. The strength of an electromagnet is:

- Directly proportional to the number of turns in the coil

- Directly proportional to the current flowing in the coil

- Inversely proportional to the length of air gap between the poles

Corresponding Author: K. Manikandan, Department of EEE, Jawahar Lal Nehru Technological University Hyderabad (JNTUH), Telegana, India 

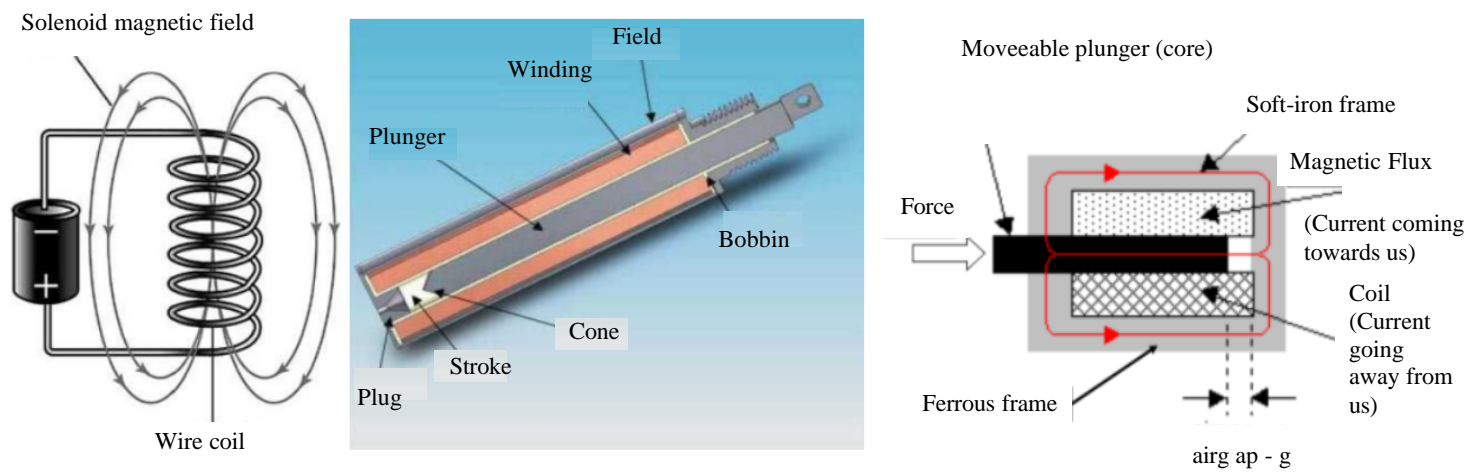

Fig. 1: Solenoid coil model diagrams

In general, an electromagnet is often considered better than a permanent magnet because it can produce very strong magnetic fields and its strength can be controlled by varying the number of turns in its coil or by changing the current flowing through the coil(Fig. 1):

- Force $=\mathrm{Kf}$ (constant) $\times($ Number of turns $\times$ Coil current $)^{2} /(\text { Gap width })^{2}$

- The main components of disc brake is thebrake pads, the caliper which contains a piston

- Therotor which is mounted to the hub, hand brake and solenoid

The disc brake is a similar as on abicycle. Bicycle brakes have a caliper which squeezes the brake pads against the wheel. When the brake pedal is applied, pressurized hydraulic fluid squeezes the brake pad friction material against the surface of the rotating brake disc. Friction between the pads and the disc slows the disc down by using push pull DC solenoid.

\section{RESULTS AND DISCUSSION}

\section{IoT and value engineering}

Internet of things: Various names, one concept:

- $\quad \mathrm{M} 2 \mathrm{M}$ (Machine to Machine)

- "Internet of everything" (Cisco systems)

- "World size web" (Bruce schneier)

- "Skynet" (Terminator movie)

Here, we are discussed about IoT based remote control and value engineering the previous one. In IoT remote access, IoT can bridge the gap between a wind farm located several hours or even days away and a local control center with access, so, attendants might adjust switches, software or equipment from a distance. IoT

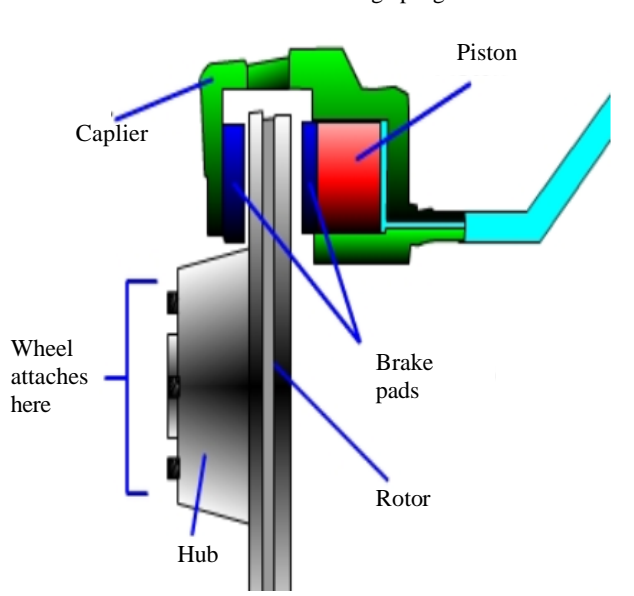

Fig 2: Rotor with brake pads Ref: How stuff works: Ver

gives wind-farm operators control to monitor and regulate much of a turbine's operation no matter how much distance separates the two.

This principle is employed in the magnetic brake for speed control in the wind turbine system. For obtaining the functioning capability of magnetic brake analytically, we need to calculate the power and hence, torque of rotor against the speed of revolution (Fig. 2).

Block diagram: End to end IOT solution development requires a broad range of skills including embedded system design, cloud architecture, application, data analytics, security design and back-end system integration (Fig. 3).

Wind turbine brake system sketch: Nylon spacers, washers and a nut to secure the solenoid (Fig. 4).

Value engineering basic: Structured value engineering job consists of six steps:

- Information phase

- Creativity phase

- Evaluation phase

- Planning phase 


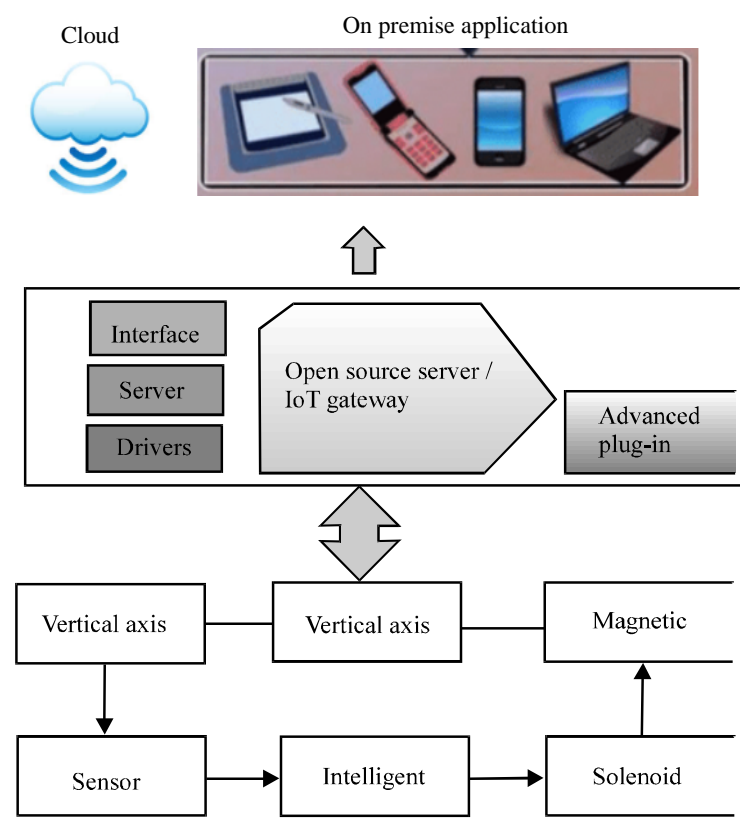

Fig. 3: Sketch of block diagram of the proposed system

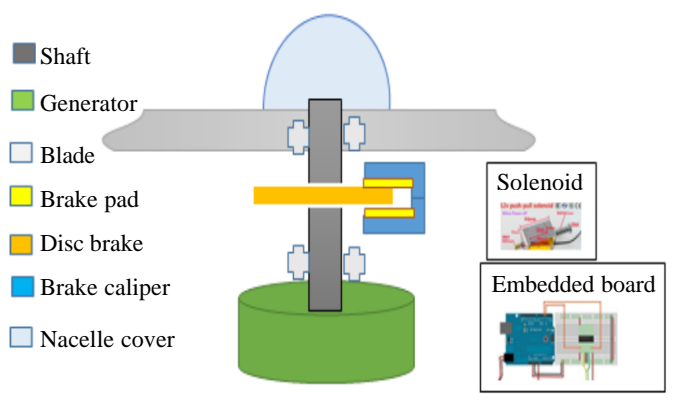

Fig. 4: Sketch of a typical WT brake system

- Reporting phase

- Implementation phase

SWOT: First initiate the SWOT analysis for concept evaluation report (SWOT). To measure the true values in any product ask these questions:

- What is it?

- What does it do?

- What does it cost?

- What else will do the job?

- What will that cost?

- What is the Most Valuable way?

After calculating extended cost, one should perform an $\mathrm{ABC}$ analysis. This analysis sorts the cost into three categories by their percentage contribution to the total cost.

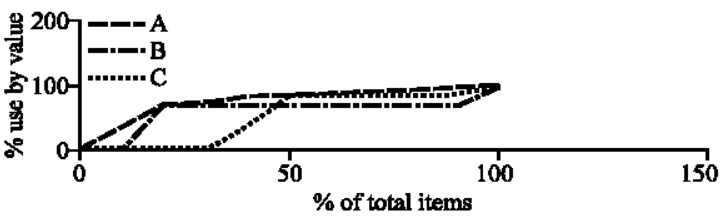

Fig. 5: $A B C$ cost value:a) class items existing design which represent about $10-15 \%$ of the total parts count but account for $70 \%$ of the total product cost; b) Class items embedded circuit which represent the next $20 \%$ of the total parts count and the next $20 \%$ of the total product costs (for a total of $90 \%$ and c) Class items Embedded circuit with IoT which represent $70 \%$ of the total items but only about $10 \%$ of the total cost

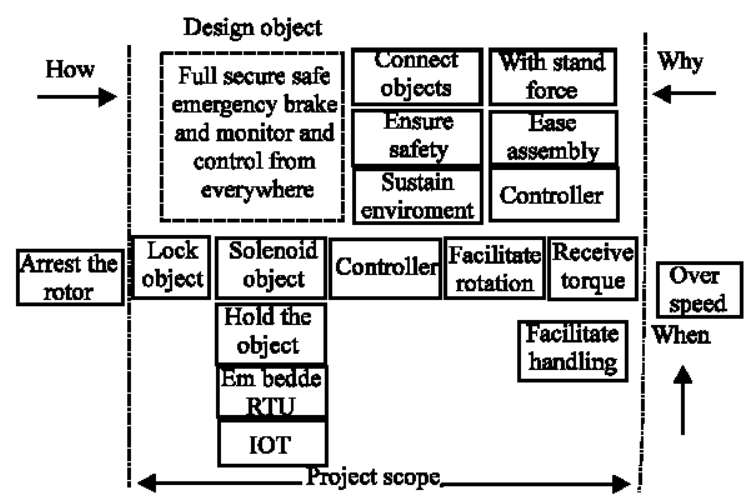

Fig 6: Fast diagram

SWOT analysis: Table 1 contains an example of this type of analysis on a sample electrical assembly (Fig. 5).

Function phase: Specific purposes or intended use of an item (What is this? What is it supposed to do? What else can it do?). It is divided into feature-function matrix, function cost allocation, consolidated feature-function matrix, technically oriented fast diagram and function cost worth analysis (Table 2-4).

Technically oriented fast diagram: Figure 6 shown in technically fast diagram.

Concept evaluation: Predetermined minimum method, parameters considered in the following. Performance, ease of operation, ease of manufacturing, monitor and control for the module, ease of maintenance (Table 5).

Cost benefit analysis: As shown in Table 6 product cast savings. 
Int. J.Elec. Power Eng., 12 (2): 15-19, 2018

Table 1: Analysis of sample electrical assembly

\begin{tabular}{|c|c|c|c|c|c|c|}
\hline \multirow{2}{*}{\multicolumn{2}{|c|}{ Product cost estimation }} & \multicolumn{5}{|c|}{ Information phase } \\
\hline & & \multicolumn{5}{|c|}{ Cost estimation of DC solenoid disc brake in Rs } \\
\hline Level & Component name & Materials cost & Mfg cost & Cost/piece & Quantity & Total cost \\
\hline 0 & DCS disc Brake Assy & - & - & - & 1 & 9.120 \\
\hline 1 & Embedded Board Assy & & & & 1 & 3.540 \\
\hline 2 & Embedded Circuits & 600 & 1000 & 1600 & 2 & 3200 \\
\hline 2 & Distance Tube & 10 & 20 & 30 & 2 & 60 \\
\hline 2 & Nut & - & - & 20 & 4 & 80 \\
\hline 2 & Washer & - & - & 10 & 4 & 40 \\
\hline 2 & Bolt & - & - & 40 & 4 & 160 \\
\hline 1 & Solenoid Assy & & & & 1 & 1200 \\
\hline 2 & Solenoid & 400 & 500 & 900 & 1 & 900 \\
\hline 2 & Power Circuit & - & - & 250 & 1 & 250 \\
\hline 2 & Stand & - & - & 50 & 1 & 50 \\
\hline 1 & Brake Handle Assy & & & & 1 & 2500 \\
\hline 2 & Brake Handle & 600 & 500 & 1100 & 1 & 1100 \\
\hline 2 & Brake Pad & 200 & 100 & 300 & 2 & 600 \\
\hline 2 & Brake Caliper & 500 & 300 & 800 & 1 & 800 \\
\hline 1 & Top Link Pin Assy & & & & 1 & 940 \\
\hline 2 & Top Pipe Pin & 400 & 300 & 700 & 1 & 700 \\
\hline 2 & Nut & - & - & 20 & 4 & 80 \\
\hline 2 & Bolt & - & - & 40 & 4 & 160 \\
\hline 1 & Bottom Link Pin Assy & & & & 1 & 940 \\
\hline 2 & Bottom Pipe Pin & 400 & 300 & 700 & 1 & 700 \\
\hline 2 & Nut & - & - & 20 & 4 & 80 \\
\hline 2 & Bolt & - & - & 40 & 4 & 160 \\
\hline
\end{tabular}

Table 2: Function level

\begin{tabular}{|c|c|c|c|c|c|c|c|}
\hline \multirow[b]{2}{*}{ Product name } & \multirow[b]{2}{*}{ Sub-assembly } & \multirow[b]{2}{*}{ Component name } & \multirow[b]{2}{*}{ Feature } & \multirow[b]{2}{*}{ Type function (Use/Sell) } & \multicolumn{2}{|l|}{ Function } & \multirow[b]{2}{*}{$\begin{array}{l}\text { Function level } \\
\text { (Basic/Secondary) }\end{array}$} \\
\hline & & & & & Verb & Noun & \\
\hline \multirow{6}{*}{ DCS rotor lock } & & & & Use & Lock & Object & Basic \\
\hline & & & & Use & Withstand & Force & Secondary \\
\hline & & & & Use & Ensure & Ensure & Basic \\
\hline & & & & Use & Ease & Safety & Secondary \\
\hline & & & & Use & Sustain & Assembly & Secondary \\
\hline & & & & Use & Facilitate & Environment & Handling \\
\hline DCS rotor lock & Embedded assy & & & Use & Lock & Object & Basic \\
\hline DCS rotor lock & & & & Use & Withstand & Signal & Secondary \\
\hline DCS rotor lock & & & & Use & Ensure & Safety & Basic \\
\hline DCS rotor lock & & & & Use & Maintain & Gap & Secondary \\
\hline DCS rotor lock & & & & Use & Facilitate & Handling & Secondary \\
\hline DCS rotor lock & & & & Use & Ease & Assembly & Secondary \\
\hline
\end{tabular}

Table 3: Function cost allocation in RS

\begin{tabular}{|c|c|c|c|c|c|c|}
\hline \multirow[b]{2}{*}{ Component } & \multirow[b]{2}{*}{ Component cost } & \multicolumn{2}{|l|}{ Function } & \multirow[b]{2}{*}{ Type B/S } & \multicolumn{2}{|c|}{ Cost allocation } \\
\hline & & Verb & Noun & & Basis & Cost \\
\hline \multirow[t]{4}{*}{ Embedded board } & 3540 & Lock & Object & B & Hole & 3200 \\
\hline & & Withstand & Force & $\mathrm{s}$ & Thickness & 60 \\
\hline & & Facilitate & Handling & $\mathrm{s}$ & Shape & 80 \\
\hline & & Ease & Assembly & $\mathrm{s}$ & Shape & 40 \\
\hline \multirow[t]{4}{*}{ Dc solenoid } & 1200 & Facilitate & Handling & B & Shape & 160 \\
\hline & & Withstand & Force & $\mathrm{s}$ & Dia & 900 \\
\hline & & Position & Object & $\mathrm{s}$ & Length & 250 \\
\hline & & Ease & Assembly & $\mathrm{S}$ & Head & 50 \\
\hline
\end{tabular}

Table 4: Consolidated feature function matrix functions

$$
\text { Components }
$$

\begin{tabular}{lcccccc} 
Function & Embedded board & DCS & Brake handle & Brake caliper & Brake pad & Electric circuit Assy \\
\hline Lock object & $\Delta$ & & & & $\Delta$ \\
Ensure Safety & $\Delta$ & $\Delta$ & $\Delta$ & $\Delta$ & $\Delta$ & $\Delta$ \\
$\begin{array}{l}\text { Facilitate handling } \\
\text { Facilitate rotation }\end{array}$ & $\Delta$ & & $\Delta$ & $\Delta$ & $\Delta$ \\
Increase area & & & & & $\Delta$ \\
\hline
\end{tabular}


Int. J. Elec. Power Eng., 12 (2): 15-19, 2018

\begin{tabular}{|c|c|c|c|c|c|c|}
\hline \multirow[b]{2}{*}{ Function } & \multicolumn{6}{|l|}{ Components } \\
\hline & Embedded board & DCS & Brake handle & Brake caliper & Brake pad & Electric circuit Assy \\
\hline \multicolumn{7}{|l|}{ Hold object } \\
\hline Maintain gap & & $\Delta$ & & & & \\
\hline Connect object & & & $\Delta$ & $\Delta$ & $\Delta$ & \\
\hline Adjust length & & & & & $\Delta$ & \\
\hline Ease assembly & $\Delta$ & & & & & $\Delta$ \\
\hline Withstand force & $\Delta$ & $\Delta$ & $\Delta$ & $\Delta$ & $\Delta$ & $\Delta$ \\
\hline Position object & & $\Delta$ & $\Delta$ & $\Delta$ & $\Delta$ & $\Delta$ \\
\hline Receive torque & & & & & $\Delta$ & \\
\hline Sustain environment & $\Delta$ & $\Delta$ & $\Delta$ & $\Delta$ & $\Delta$ & $\Delta$ \\
\hline
\end{tabular}

\begin{tabular}{|c|c|c|c|c|}
\hline Parameter & Key letter & Max. points & $\begin{array}{l}\text { Min points for } \\
\text { the acceptance }\end{array}$ & $\begin{array}{l}\text { Balance } \\
\text { points }\end{array}$ \\
\hline Performance & A & 100 & 80 & 20 \\
\hline $\begin{array}{l}\text { Ease of } \\
\text { operation }\end{array}$ & B & 100 & 60 & 40 \\
\hline $\begin{array}{l}\text { Ease of } \\
\text { manufacture }\end{array}$ & $\mathrm{C}$ & 100 & 50 & 50 \\
\hline $\begin{array}{l}\text { Control and } \\
\text { monitor }\end{array}$ & $\mathrm{D}$ & 100 & 80 & 20 \\
\hline $\begin{array}{l}\text { Ease of } \\
\text { maintenance }\end{array}$ & $\mathrm{E}$ & 100 & 50 & 50 \\
\hline
\end{tabular}

Table 6: Product cost savings

\begin{tabular}{lcl}
\hline Concept name & Product cost (Rs) & $\begin{array}{l}\text { Savings w.r.to } \\
\text { existing }\end{array}$ \\
\hline Existing & 18.500 & - \\
Embedded controller & 12.500 & $\sim 6000$ \\
Embedded controller with & 9.540 & $\sim 2960$ \\
IoT(implement all the area) & & \\
\hline
\end{tabular}

\section{CONCLUSION}

From the experimental and analyze the results the following conclusion can be drawn. The hydraulic brake control system developed in this research worked well during the functional analysis test using the test bed in the laboratory. When initial rotational speed of the brake disc is $600 \mathrm{rpm}$ it can be stopped in $1.2 \mathrm{sec}$. In future IoT based monitoring improves efficiency of operation and reduced cost value.

\section{REFRERENCES}

Anonymous, 2018. Vertical axis wind turbines. Conserve Energy Future, USA. http:// www. conserve-energy-future.com/verticalaxiswindturbin es.php

Froese, M., 2016. Talking with turbines through the internet of things. WTWH Media, LLC., Cleveland, Ohio. https://www-controls-networks./ talking-turbines-internet-things/

Hodge, N., 2012. The truth about energy: Taking sides is costing you money. Energy and Capital, Baltimore, Maryland. https://www. energyandcapital.com/articles/the-truth-about-ener gy $/ 2535$

IEC., 2005. Wind Turbines-Part 1s: Design Requirements. 3rd Edn., International Electrotechnical Commission Publisher, Geneva, Switzerland,

Jee, I.H., S.Y. Nahm, S.J. Kang and K.S. Ryu, 2012. A magnetic brake for small wind turbines. J. Magn., 17: 33-35.

Meeker, D. and F.J. McWilliams, 2003. Structured Cost Reduction Value Engineering by the Numbers. Massachusetts Institute of Technology (MIT), Cambridge, Massachusetts, USA., 